\title{
Long-term variability of solar irradiance and its implications for photovoltaic power in West Africa
}

Ina Neher ${ }^{1,2}$, Susanne Crewell ${ }^{2}$, Stefanie Meilinger ${ }^{1}$, Uwe Pfeifroth ${ }^{3}$, Jörg Trentmann ${ }^{3}$
1 University of applied science Bonn-Rhein-Sieg, 2 University of Cologne, 3 German weather service (DWD)

Contact: ina.neher@h-brs.de

Neher et al. (2020), submitted to ACP

\section{Solar power for West Africa}

- Solar power can serve the rising global energy demand with low environmental impact.

- West Africa is rich in global horizontal irradiance (GHI) and power generation is lacking.

- Satellite data for GHI can serve as input for a linear photovoltaic (PV) power model, processed with measured data (see Fig. 1).

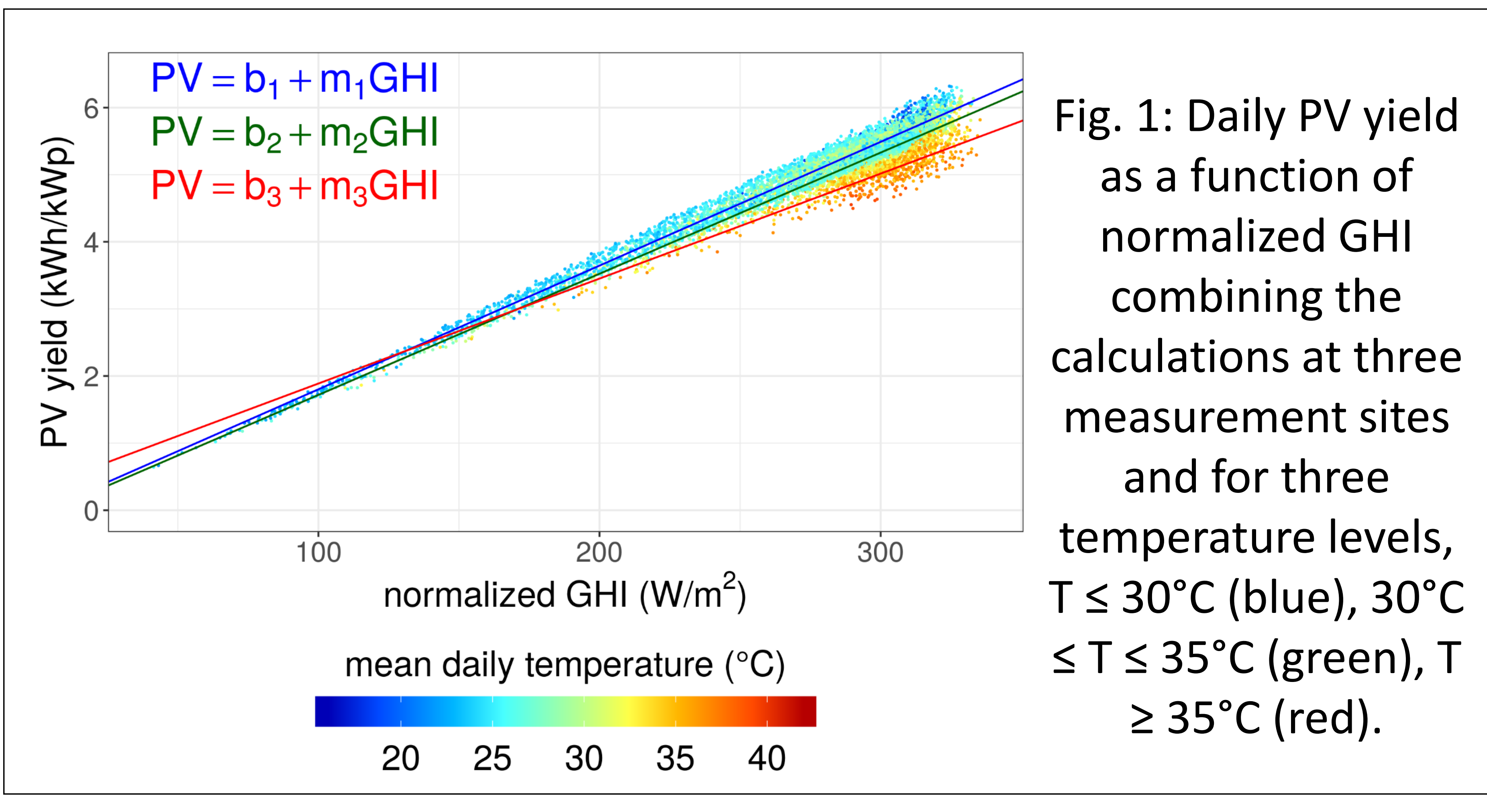

2 Surface Solar Radiation Data Set - SARAH-2.1

- Satellite retrieval of $\mathrm{GHI}$ in a daily resolution between 1983 and 2017.

- Comparison of satellite data to measurements in Agoufou (Mali), Banizoumbou (Niger) and Djougou (Benin) (Fig. 2, AMMA dataset).

- RMSE: $20-34 \mathrm{~W} / \mathrm{m}^{2}$; better agreement in Agoufou and Banizoumbou than in Djougou.

- Normalization of GHI with minimal daily zenith to model PV power.


Fig. 3: Mean GHI (a) and linear trend for all seasons (b), the wet (c) and the dry season (d) between 1983 and 2015.

3 PV potential between 1983 and 2017 and trends

- High potential in Sahel region and Sahara $\left(\mathrm{GHI}>250 \mathrm{~W} / \mathrm{m}^{2}\right.$, Fig. 3 a); PV yield $>5$ kWh/kWp, Fig. 4 a).

- Positive trend of GHI in the Sahara, marginal trend in Sahel zone and negative trend in Southern West Africa (Fig. 3 b).

- Positive trend of GHI mainly during dry season (October to April, Fig. 3 c).

- Negative trend of GHI mainly during wet season (Mai to September, Fig. $3 \mathrm{~d}$ ).

Fig. 4: Mean PV yield at each latitude, for the total year (a) as well as for the dry (dark) and wet (light) season (b), in the longitude range between $4^{\circ} \mathrm{W}$ and $4^{\circ} \mathrm{E}$. The points in (a) mark the mean PV yield calculated with explicit model at Agoufou (2005-2008),

Banizoumbou (2005-

2012) and Djougou (20022009).
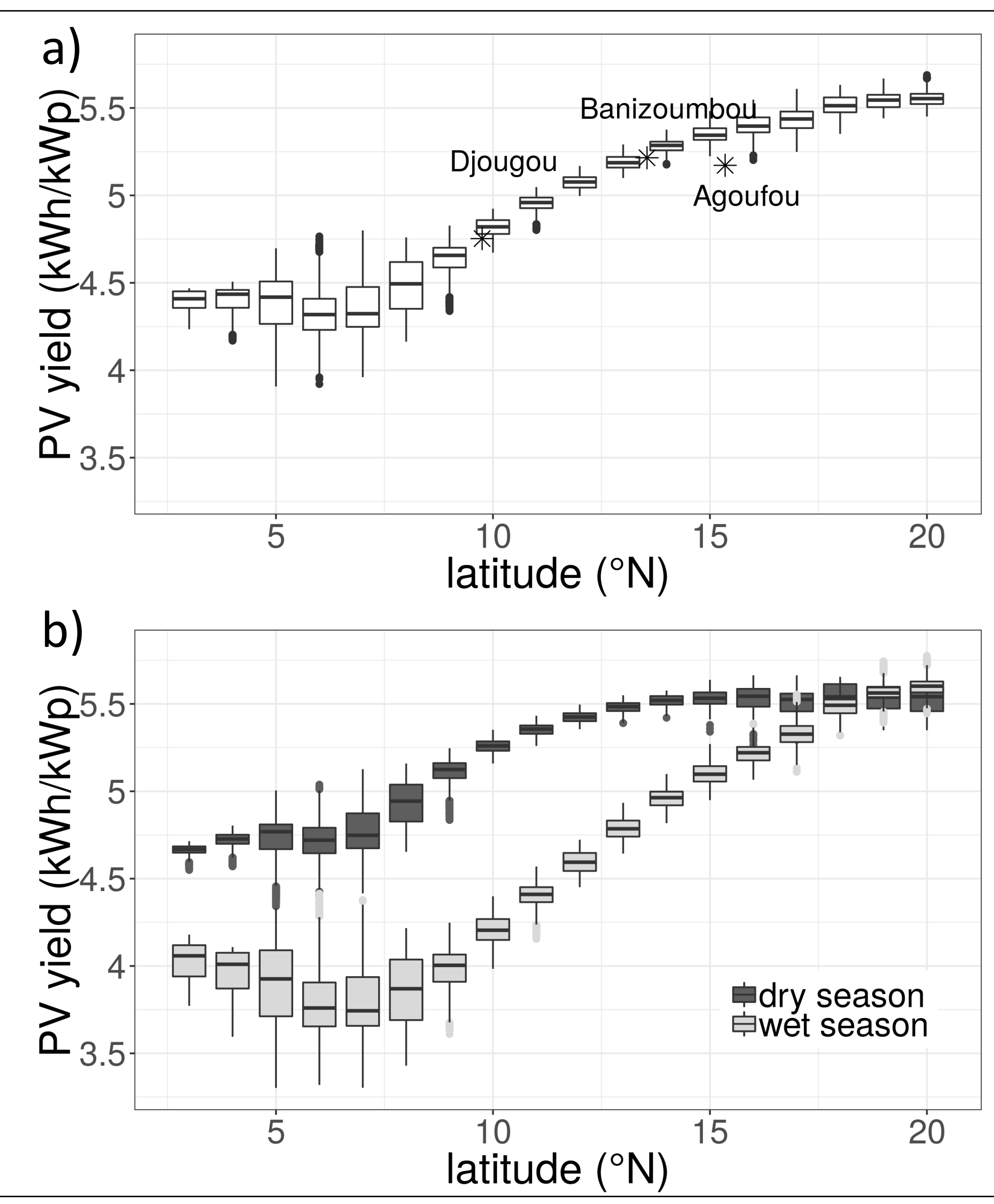

\section{Conclusion}

- Decrease of GHI during wet seasons (likely due to the increase of cloud cover) and increase during dry season (likely due to lower dust movement and clouds).

- PV potential increased over time in regions with low urban density and decreased in regions with high urban density.

- For a solar based electricity system in West Africa, NorthSouth grid and seasonal storage capacities are needed. 